\title{
EXPLORAÇÃO TEÓRICA PARA A INVESTIGAÇÃO DA INTERFACE ENTRE O POLÍTICO E O ECONÔMICO: ELITISMO, PLURALISMO E MARXISMOS
}

Pedro Felipe Narciso ${ }^{1}$

\begin{abstract}
Resumo
O trabalho a seguir compõe a etapa exploratória de uma pesquisa ainda em andamento, cujo resultado deverá ser uma dissertação de mestrado acerca das disputas que envolveram o processo de discussão e aprovação da Lei $n^{\circ} 12.351$, a qual estabeleceu o regime de partilha de produção para determinadas áreas do Pré-sal. O objetivo da referida etapa de pesquisa é o de oferecer uma avaliação crítica de diferentes arcabouços teóricos, confrontando-os no sentido de depurar seus pontos mais problemáticos, fundamentando, assim, a escolha de um instrumental teórico capaz de abarcar os processos de interação entre o político e o econômico. No que se refere aos procedimentos de pesquisa, realizou-se uma revisão bibliográfica de caráter focalizado, tendo como critério básico de busca o objetivo supracitado. Da referida revisão apreciou-se criticamente as seguintes composições teóricas: o elitismo clássico e posicional, o pluralismo e os marxismos de Ralph Miliband, Edward Thompson e Nicos Poulantzas. Dessa abordagem panorâmica sobre as diferentes possibilidades teóricas foi possível concluir que a teoria regional do político de Nicos Poulantzas é aquela que disponibiliza as ferramentas mais adequadas para a investigação da relação entre o político e o econômico.
\end{abstract}

Palavras-Chave: Teoria das elites; Pluralismo; Marxismos.

\section{Theoretical exploitation for the investigation of the interface between the politician and the economic: elitism, pluralism and marxism}

\begin{abstract}
This work comprises the exploratory stage of a research still in progress, the result of which should be a master dissertation about the disputes that involved the process of discussion and approval of Law 12.351, which established the system of sharing production for certain areas of the Pre-salt. The objective of this research stage is to offer a critical evaluation of different theoretical frameworks, confronting them in the sense of debugging their most problematic points, thus supporting the choice of a theoretical instrument capable of encompassing the processes of interaction between the political and economic. As far as the research procedures were concerned, a bibliographical review of a focused character was carried out, having as basic criterion of search the aforementioned objective. From this review the following theoretical compositions were critically appraised: classical and positional elitism, pluralism and the Marxisms of Ralph Miliband, Edward Thompson and Nicos Poulantzas. From this panoramic approach on the different theoretical possibilities it was possible to conclude that the regional theory of the politician of Nicos Poulantzas is one that provides the most appropriate tools for the investigation of the relation between the political and the economic.
\end{abstract}

Keywords: Elitism; Pluralism; Marxisms.

${ }_{1}^{1}$ Mestre em Sociologia pelo Programa de Pós-Graduação em Sociologia da Universidade Federal de Pelotas. Bacharel em Ciências Sociais pela Universidade Federal do Rio Grande do Sul. 


\section{Introdução}

O presente trabalho compõe a etapa exploratória de uma pesquisa ainda em andamento, cujo resultado deverá ser uma dissertação de mestrado acerca das disputas que envolveram o processo de discussão e aprovação da Lei n 12.351 (BRASIL, 2010), a qual estabeleceu o regime de partilha de produção para determinadas áreas do Pré-sal. O objetivo da referida dissertação é o de evidenciar a intersecção entre o econômico e o político na conjuntura em que as disputas sobre o novo marco regulatório do Pré-sal se desenvolveram, entre os anos de 2008 e 2010. Desse modo, este texto tem como objetivo fundamental oferecer uma avaliação crítica de diferentes arcabouços teóricos, confrontando-os no sentido de depurar seus pontos mais problemáticos e, com isso, fundamentar a escolha de um instrumental teórico capaz de abarcar os processos de interação entre o político e o econômico.

Observando como critério o objetivo supracitado realizou-se uma revisão bibliográfica de caráter focalizado. Dessa revisão deduziuse um conjunto de tradições teóricas, sendo essas posteriormente comparadas de modo crítico de acordo com seu potencial de investigação sobre a realidade política e econômica. As teorias observadas foram reunidas e consideradas do seguinte modo: primeiro, uma comparação entre duas grandes tradições que polarizaram as análises acadêmicas no século XX, O elitismo e o pluralismo. Posteriormente a crítica desloca-se para versões teóricas de uma tradição a qual tem como um dos seus problemas de pesquisa fundamentais justamente a relação entre o político e o econômico, trata-se do marxismo. Por fim, busca-se apresentar justificadamente a concepção teórica cujas contribuições são mais ricas no exame da relação entre aquelas duas instâncias, a teoria de Nicos Poulantzas, a qual também está inserida no campo da tradição marxista.

\section{Elitismo e pluralismo}

Nesta seção, como já anunciado na introdução, abordar-se-ão as teorias elitista e pluralista. A escolha de tais constructos teóricos para uma apreciação crítica justifica-se por dois argumentos: primeiro, porque as duas teorias polarizam o espectro teórico no que tange as considerações sobre o fenômeno político. Segundo, porque essa polarização reflete não uma diferença secundária ou 
Exploração teórica para a investigação da interface entre o político e o econômico

superficial, mas uma diferença de fundo que perpassa outras polarizações teóricas². Qual é essa diferença? A avaliação sobre o fluxo do poder político. Esse é produzido dispersamente e seus pontos de cristalização são apenas resultados fenomênicos das dinâmicas dispersas? Ou o poder político emana de um ponto nodal, sendo suas emergências dispersas momentos do centro? É em torno da transformação desse último questionamento numa verdade teórica que se constitui o elitismo, objeto dos parágrafos seguintes.

De acordo com Gimenez (2014) a teoria clássica das elites foi erigida por três autores principais: Gaetano Mosca, Vilfredo Pareto e Robert Michels. O primeiro advogava uma perspectiva de ciência social fundamentada num método histórico, o qual consistia em observar diferentes sociedades em diferentes períodos no intuito de identificar regularidades. Com tal premissa metodológica Mosca sustentou que uma das regularidades fundamentais que transcende os limites históricos das sociedades perpassando qualquer organização social que já tenha existido é - "fato" de que todas as sociedades se dividem entre uma minoria governante e uma maioria governada, uma distinção entre o que ele chamou de classe política e de massa. A justificativa teórica que o autor conferiu a tal constatação tinha um fundamento de cunho organizacional (CREMONESE, 2008), pois Mosca supôs que a inexorabilidade da dominação da maioria por uma minoria se dava justamente pela capacidade de homogeneidade, coesão e organização que só seria possível a uma minoria, visto que, na visão desse autor, as maiorias seriam definitivamente desorganizadas e motivadas por interesses individuais dispersos. Desse modo, as elites dominam porque, tendo um interesse comum e uma disposição organizativa devido ao seu tamanho reduzido, são capazes de impor-se às massas, essencialmente desorganizadas e dispersas.

Se Mosca parte de uma abordagem organizacional, Pareto propõe uma abordagem psicológica, pois para esse autor as elites se formam devido aos atributos invariavelmente desiguais que conformam os indivíduos, às suas características pessoais que conduzem certos homens para as elites e outros para a massa. De acordo com o autor, as elites se definem por um conjunto de indivíduos que tem os melhores índices de desempenho em cada

2 Um exemplo de como tal polêmica teórica atravessa também outras perspectivas nas Ciências Sociais que não apenas o mainstream da Teoria Política pode ser observado pela excelente crítica do professor Armando Boito à concepção de poder de Michel Foucault (BOITO JR, 2007).

CSOnline - Revista Eletrônica de Ciências Sociais, Juiz de Fora, n. 29 (2019) 
ramo de atividade, desse modo, as elites não se restringem ao campo da política. Nesse mesmo sentido Pareto observa a existência de elites governantes, que tomam de modo direto às decisões; as elites não governantes, que sendo dirigentes em outros âmbitos relevantes (econômico, militar) tem a capacidade de influenciar as decisões políticas; e os comandados, uma maioria totalmente apartada do processo decisório.

Tal como Mosca, Robert Michels, por sua vez, flerta com uma concepção elitista organizacional, no entanto, diferentemente daquele autor, Michels não enxerga a elite como uma minoria que se organiza para defender um interesse prévio. De acordo com o elitista alemão, quando se estabelece algum tipo de organização obrigatoriamente se deriva desse novo grupo organizado necessidades e interesses próprios, os quais se impõem sobre os objetivos e interesses que originalmente motivaram 0 processo organizativo. A rotina organizativa/administrativa do grupo organizado exige o destacamento de um número de pessoas que se especializam em tais procedimentos, esses indivíduos vão concentrando poder na medida em que pela prática os mesmos se especializam e dominam os conhecimentos e procedimentos que a maioria dos aderentes desconhece. Uma consequência incontornável desse processo é a "tecnocratização" que afasta os chefes do controle da maioria, dotando-os com um status social e moral que, na prática objetiva e na leitura subjetiva de cada um, distingue-os da massa.

Uma variante do elitismo clássico, que pode ser classificada como elitismo crítico e/ou posicional, encontra-se na obra de Charles Wright Mills (GIMENEZ, op. cit.) que, escapando das leis inexoráveis que condenam toda e qualquer sociedade à dominação da maioria por uma minoria, propõe uma análise das elites políticas num espaço e tempo determinado, sem a pretensão de deduzir dessa uma lei de ferro a-histórica. Estudando a sociedade americana da segunda metade do século XX o autor propõe uma conceituação posicional das chamadas elites, ou seja, as elites não dominam porque são mais organizadas, como em Mosca; ou porque são dotadas de uma vocação para a dominação e direção da sociedade, como em Pareto; ou então como em Michels, porque constituem tecnocracias especializadas na administração do corpo político organizacional. Para Mills, as elites são elites porque ocupam posições nas estruturas fundamentais de determinada sociedade. Assim, no caso da sociedade estadunidense essas instituições seriam o governo 
nacional, o exército e as grandes corporações. Constituindo essa premissa em torno de tais arranjos institucionais, Mills estuda a composição social dessas diferentes estruturas organizacionais no sentido de traçar as origens dessas elites e como elas se intersecionam na administração da dominação.

Estando já exposto o elitismo na sua unidade e diversidade, desde a concepção clássica até sua perspectiva crítica e posicional, passa-se a sua apreciação crítica. Começa-se, aqui, pela avaliação das proposições de cada um dos autores tomados separadamente. Sobre a proposta teórica de Mosca cabe a observação acerca da falta de cuidado em não diferenciar os conceitos de dominação e de direção, considerando àquela uma lei inerente a todas as sociedades humanas, o que não se sustenta desde uma perspectiva histórica minimamente rigorosa, da qual o próprio autor afirma partir. Outras questões que podem evidenciar a fragilidade das proposições de Mosca são: como e por que as minorias se destacam das massas? Por que algumas minorias tornam-se elites e outras, mesmo sendo minorias e, portanto, com maior potencial de coesão e organização, tornamse o contrário de elites, ou seja, grupos marginais à própria sociedade? E, por fim, qual elemento distinguiria uma minoria marginalizada de uma minoria que se constitui como elite? À Pareto recai a crítica geral do elitismo que depois será retomada, a saber, uma justificação tautológica e fatalista da existência de elites que contribui muito pouco para observação de objetos históricos e concretos, pois suas conclusões já residem em suas premissas: as elites dominam porque possuem os atributos necessários ao exercício da dominação, a qual é inevitável. Que atributos são esses? Nasce-se com eles ou são adquiridos? Se adquiridos, como? No que tange a Michels, percebe-se uma evolução teórica em relações aos outros dois, pois o autor oferece uma boa hipótese sobre o processo de distanciamento das cúpulas de suas bases, ou seja, o processo de autonomização do político. O erro, no entanto, é absolutizar essa autonomia, caindo no erro geral do elitismo, ou seja, tomar o político como sistema fechado acoplado no espaço vazio que se explica única e exclusivamente por uma dinâmica interna sem interação com o entorno. Percebe-se que não se pode explicar pelo elitismo clássico o porquê de determinadas elites terem características de gênero, de etnia ou de classe tão marcadas. Não se pode explicar também pelo elitismo clássico o fato das elites, ao substituírem-se no poder, perseguirem objetivos tão diferentes, ou 
seja, se elas representam somente seus próprios interesses, por que motivo perseguem finalidades tão distintas? (SAES, 1994). Enfim, percebe-se desde já que se o objetivo desse trabalho é observar a relação entre classes sociais e o Estado, a teoria das elites pode ser descartada, pois essa não enxerga a menor intersecção entre as categorias econômicas e políticas, impossibilitando, portanto, uma análise que transcenda os limites de uma ciência política estreita e monodimensional.

Parte da crítica exposta até aqui não se aplica a proposta de Mills, sobretudo no que se refere à intersecção das elites. No entanto, a teoria de Mills sobre a composição das elites políticas, militares e econômicas nos EUA é meramente descritiva, apenas indica as características compartilhadas pelos indivíduos que compõe tais elites, não explicando a partir de uma articulação teórica o que efetivamente torna essas, de fato, o que elas são. A explicação posicional, em que as elites são assim definidas por ocupar posições nas cúpulas de poder das instituições fundamentais é tão circular quanto à argumentação dos clássicos, portanto, também se descarta ${ }^{3}$.

Se o equívoco teórico da teoria das elites é desvincular o poder político do conjunto das outras esferas sociais, o equívoco pluralista se dá justamente pelo oposto, ou seja, por dissolver o poder político de modo indiferenciado nos chamados grupos de interesse e/ou pressão. Embora reconheça que "a desigualdade de poder é uma característica de todos os sistemas sociais" (DAHL, 2012, p. 433), consiste um erro da parte de Dahl negligenciar o estudo sobre os processos que distribuem esse poder de modo desigual. Portanto, se os sistemas sociais distribuem poderes desigualmente é preciso investigar esses sistemas de distribuição, para tal não é possível reduzir a complexidade social num conjunto de grupos de pressão, como se o poder fosse aleatoriamente distribuído sem qualquer processo estruturante que garanta unidade e permanência no modo como - poder político é desproporcionalmente divido e, consequentemente, acumulado (obviedade negligenciada pelo pluralismo). A teoria pluralista é incapaz de explicar os padrões na constituição de centros desproporcionais de poder por se utilizar de uma categoria totalmente abstrata, vazia de conteúdo real, os grupos de pressão. A conclusão que se chega é a de que a teoria pluralista é um reflexo teórico do efeito de isolamento

${ }^{3}$ Essa discussão será retomada na abordagem da obra de Ralph Milband, que busca incorporar o elitismo de Mills numa perspectiva marxista. 
(POULANTZAS, 1977) produzido pela estrutura jurídico-política do Estado, ou seja, ela toma o efeito ideológico de equalização abstrata da desigualdade real como premissa própria da realidade, nesse sentido, reduz as diferenças concreto-reais - por exemplo: sindicato de bancários e confederação de banqueiros ao mesmo conceito puramente formal de grupo de pressão ou interesse, desconsiderando os fundamentos que distribuem desigualmente poder político nas sociedades as quais se propõem a observar. Portanto, assim como o elitismo, o pluralismo não é útil para verificar a relação entre o político e o econômico.

\section{Os marxismos de Miliband e de Thompson}

Concluída à crítica aos extremos hegemônicos na Teoria Política, urge a necessidade de propor uma alternativa teórica. Entendendo, então, que à elaboração de uma problemática de pesquisa acompanha uma delimitação temática, na qual, por sua vez, acaba por definir de modo mais ou menos restrito as possibilidades e impossibilidades teóricas para o exercício da pesquisa, afirma-se que as problemáticas que se inserem no campo de articulação do político com o econômico considerando a categoria de classe social são típicas da tradição teórica do marxismo, portanto, cabe observar, também, a referida tradição, obviamente, com o mesmo rigor crítico.

Ao conceber o marxismo no seu sentido lato, ou seja, como uma ampla tradição que abarca perspectivas diversas e, muitas vezes, contraditórias, nota-se a mobilização de uma multiplicidade de temas, problemas e, até mesmo, disciplinas. Porém, recorrendo a alguns critérios na definição daquilo o que é de fato marxismo, essa massa teórica quase indefinível ganha uma forma, com fundamentos, problemática, disciplinas derivadas com fronteiras definidas, etc. (ALTHUSSER, 2015). Essa discussão, no entanto, não ganha relevância nesse momento, o fato para o qual se chama a atenção é que a problemática da interação entre o político e o econômico mostra-se como uma das partes constitutivas do marxismo, fazendo-se presente desde a própria pré-história dessa tradição teórica, vide textos tais como A Crítica da Filosofia do Direito de Hegel (MARX, 2010); aparecendo também na maturação teórica da tradição, vide O Manifesto do Partido Comunista (MARX e ENGELS, 2011); no seu processo de maturação em estado aplicado, vide textos tais como O Dezoito do Brumário de Luís Bonaparte (MARX, 2008); e ganha, por fim, o seu 
estabelecimento como marco clássico para uma teoria geral, com o texto de Engels, A origem da Família, da Propriedade Privada e do Estado (ENGELS, 1981), e a posterior sistematização de Lênin com o O Estado e a Revolução (LENIN, 2010). Portanto, trata-se de uma temática cujo aparecimento não se estabelece como mera contingência na referida teoria, sendo aquela mesma, como já afirmado, um elemento constitutivo e, portanto, fundamental dessa tradição desde os seus primeiros desenvolvimentos. Estando exposta a centralidade de tal temática na tradição marxista, não se tem aqui o intuito de se reconstituir minuciosamente o desenvolvimento do referido tema na história teórica do marxismo. Assim, parte-se já para a apreciação das concepções daqueles que, reconhecidos como marxistas, mais impactaram o pensamento sobre a interseção do político com o econômico no desenvolvimento da teoria, estando já numa tarefa diferenciada em relação aos "clássicos", pois, não se tratava mais (para aqueles) de estabelecer os fundamentos, mas de desenvolvê-los para a operação de análises cada vez mais científicas do real. Com bases nesses critérios considera-se para a apreciação crítica Nicos Poulantzas, Edward Thompson e Ralph Miliband, autores que dialogaram de modo ativo e crítico entre si, disputando a legitimidade sobre a reorganização de centralidades conceituais e metodológicas no seio da tradição teórica do marxismo.

Começar-se-á, a partir de agora, pela avaliação das contribuições de Ralph Miliband, do qual se destaca como o objeto das observações a seguir a obra O Estado na Sociedade Capitalista, publicada no ano de 1969. No texto citado, Miliband parte de uma consistente crítica à teoria pluralista perspectivando hibridizar a sua antípoda teórica, o já mencionado elitismo (crítico e posicional, nesse caso), com uma perspectiva marxista, a qual se faria presente por uma ênfase na crítica do capitalismo, no conceito de classe social e no objetivo fundamental do Estado no capitalismo. Para o autor as sociedades capitalistas avançadas ${ }^{4}-$ universo particular sobre o qual ele restringe a análise - seriam compostas por uma pluralidade de elites econômicas, as quais se constituiriam como classe por meio "de um elevado grau de coesão e solidariedade, com interesses e objetivos comuns que transcendem bastante suas diferenças específicas e suas discordâncias" (MILIBAND, 1972, p.66). É dessa constatação que o autor formula a pergunta central que conduz sua exposição: seria

${ }^{4}$ Estados Unidos, Alemanha Federal, Japão, França e Grã-Bretanha. 
essa classe dominante também uma classe dirigente? Na perspectiva do autor sim, pois, uma parte dessa classe dominante seria formada por uma elite administrativa e burocrática cujos membros seriam recrutados nos estratos econômicos mais altos por meio da seletividade típica dos sistemas educacional (o acesso restrito às universidades de excelência, por exemplo) e admissional dos quadros burocráticos do Estado (concursos, indicações e cooptações). Nesse sentido, o Estado é definido como um "número de determinadas instituições que em seu conjunto constituem a sua realidade e que interagem como partes daquilo que pode ser denominado sistema estatal" (Ibidem, p.67), tais instituições seriam a) o governo central, b) o quadro administrativo, c) as forças militares e policiais, d) o judiciário e e) os governos subcentrais e suas respectivas assembleias legislativas. O que determinaria a unidade de funcionamento desse sistema múltiplo seria justamente a composição das cúpulas de tais instituições, as quais seriam ocupadas quase que integralmente por indivíduos que compartilham de uma mesma origem social, ou seja, uma mesma situação de classe que lhes ofereceu uma formação educacional e um status social semelhantes, bem como uma mesma rede de contatos, a qual é reforçada por processos de parentesco, amizade e identificação. Dessa situação de classe, deriva-se, então, uma perspectiva positiva sobre o capitalismo, a qual fornece a unidade de objetivos do sistema estatal, pois suas instituições - controladas por essa elite administrativa - se articulam, em último caso, sempre em torno do mesmo ponto nodal, a reprodução das sociedades capitalistas, portanto, o objetivo inescapável dos diferentes sistemas estatais "tem sido sempre, e acima de tudo, o de impedir o surgimento, onde quer que seja, de regimes fundamentalmente opostos à empresa capitalista e determinados a terminar com ela" (Ibidem, p.109).

A obra apresentada no parágrafo anterior - O Estado na Sociedade Capitalista - traz ao debate sobre o Estado capitalista contribuições de suma importância, seja pelo esforço em definir as instituições que compõe o sistema estatal, seja pela a investigação acerca da composição dos altos escalões administrativos no universo pesquisado ou pela mobilização de importante material empírico que embasa as inferências do autor. Desse modo, o livro de Miliband pode ser considerado leitura obrigatória para todos aqueles que contemporaneamente se dispõem a pesquisar sobre a problemática da interface do político com o econômico no capitalismo. No entanto, apesar de 
sua relevância, é importante frisar um aspecto levantado já por Poulantzas (2008) acerca de tal obra, o fato de que essa não contém propriamente uma problemática teórica, ou seja, não oferece uma sistematização específica de conceitos e categorias cuja mobilização posterior pudesse sustentar a observação de outros objetos concretos. Portanto, trata-se fundamentalmente de um trabalho de sondagem empírica que apresenta bons lampejos teóricos (insights e hipóteses) que, no entanto, carecem de trato teórico sistemático. Do ponto de vista propriamente teórico, é passível de crítica também a dissolução das elites administrativas no interior da classe dominante, pois a inobservância de distinção entre a classe dominante, as classes reinantes e outras categorias e camadas sociais dificultam o exame das contradições entre elas, as quais parecem mobilizar a dinâmica entre o político e o econômico. Desse último comentário deriva-se outro ponto pertinente, a noção de que as elites constituiriam uma classe homogênea e esclarecida sobre sua própria situação, controlando o sistema estatal como um instrumento passivo. Considera-se que tal noção também constitui uma simplificação, que pode obstruir a possibilidade de pesquisa sobre a mobilização do sistema estatal no sentido desse mesmo organizar, enquadrar ou disciplinar setores específicos das referidas elites num fluxo de orientação diretiva que parte do Estado e não da classe dominante "homogênea e autoconsciente". Por fim, como último comentário, além da teoria elitista de Mills, as propostas de Miliband sobre o funcionamento do Estado parecem dialogar bastante com o aparato conceitual de Pierre Bourdieu (1996), pois o funcionamento estatal desde Miliband poderia ser traduzido para o léxico bourdiano do seguinte modo: as classes que compõe o alto escalão do sistema estatal e conduzem o seu funcionamento compartilham de um habitus de classe dado pelas semelhanças de capital econômico, capital cultural e capital social. Entretanto, no pensamento de Miliband, esse habitus parece produzir-se apenas fora do político, sendo esse um espaço vazio incapaz de estruturar os "agentes" que o habitam, sendo, portanto, um espaço passivo colonizado por agentes constituídos desde fora.

No que se refere a Thompson, considera-se que o autor também traz contribuições relevantes, sobretudo, ao reconstituir um período importante da história inglesa e da gênese histórica do operariado em seus elementos cotidianos. No entanto, o autor diz pouco sobre $\bigcirc$ Estado, sendo suas considerações mais importantes 
àquelas que versam ou sobre conceito de classe social ou sobre os fundamentos epistemológicos e metodológicos do marxismo. Enquanto historiador, o autor inglês orienta a sua fundamentação, principalmente, pelos textos históricos de Marx, pelos quais pretende justificar uma perspectiva de classe social desvinculada de qualquer estruturação sincrônica nas quais os agentes sociais estariam compulsoriamente dispostos servindo de algum modo a uma lógica que lhes escapasse. Para o autor inglês as classes não existem em nenhuma teoria do modo de produção, apenas nas próprias dinâmicas históricas e aleatórias das formações sociais. Thompson entende a classe social como "um fenômeno histórico, que unifica uma série de acontecimentos díspares e aparentemente desconectados, tanto na matéria-prima da experiência como na consciência" (THOMPSON, 2004, p. 9), nesse sentido, não concebe "a classe como uma estrutura, nem mesmo como uma categoria, mas como algo que ocorre efetivamente (e cuja ocorrência pode ser demonstrada) nas relações humanas" (Ibidem, p. 9).

Assim, as classes sociais como dado ou categoria não existem como tal, o que de fato existe são uma série de experiências compartilhadas por agrupamentos humanos que, de tais experiências, podem desenvolver ou não uma identidade mobilizadora comum, que transforma uma massa indistinguível de indivíduos numa classe social. Nas palavras do historiador inglês

\begin{abstract}
A classe acontece quando alguns homens, como resultado de experiências comuns (herdadas ou partilhadas), sentem e articulam a identidade de seus interesses entre si, e contra outros homens cujos interesses diferem (e geralmente se opõe) dos seus. A experiência de classes é determinada, em grande medida, pelas relações de produção em que os homens nasceram - ou entraram involuntariamente. A consciência de classe é a forma como essas experiências são tratadas em termos culturais: encarnadas em tradições, sistemas de valores, ideias e formas institucionais. (Ibidem, p.10)
\end{abstract}

Para Thompson, portanto, a classe não se produz numa possível dinâmica objetiva da história ou do modo de produção, mas na interação de diversos agentes sociais entre si sob condições totalmente singulares. Trata-se, portanto, antes de qualquer coisa, de uma perspectiva tipicamente historicista. Essa perspectiva, com a pretensão de abordar o real na sua complexidade múltipla, 
defende que esse real só pode ser investigado na sua complexidade concreta, enquanto uma singularidade absoluta, na qual todos os elementos compartilham equitativamente do mesmo potencial explicativo. Observa-se tal postulado no excerto de Thompson citado abaixo:

\begin{abstract}
Veem-se, com frequência, praticantes teóricos, reunidos em aplicados grupos, questionando as categorias. Mas devido aos seus bloqueios empíricos, são incapazes de interrogar o ponto (na sociedade ou na história) em que essas categorias se cruzam. Em lugar de interrogar uma categoria, interrogaremos uma mulher. Será, pelo menos, mais agradável. Vamos supor que essa mulher seja a "esposa" de um homem, a "amante" de outro, a "mãe" de três filhos em idade escolar. Operária numa confecção de roupas e "representante" de seus colegas, é "tesoureira" da seção local do Partido Trabalhista e, nas noites de quinta-feira, é "segundo violino" numa orquestra amadora. De constituição forte (necessariamente) mas sofre de uma disposição depressiva levemente neurótica. É também (quase me esqueço) membro da Igreja Anglicana, e uma "comungante" ocasional. (THOMPSON, 1981, p.167)
\end{abstract}

O que o historiador inglês quer dizer com tal parágrafo? Primeiro, que a realidade pode ser apreendida em toda a sua complexidade por meio de um empirismo ingênuo; segundo, que todos esses papeis desempenhados por certo indivíduo determinam de modo equivalente a sua existência e, como se não bastasse, devem ocupar - de modo também equivalente papel central em uma teoria da história. Afirma-se aqui, entretanto, que $O$ arcabouço marxista, especialmente 0 materialismo-histórico, não pode ser reduzido a uma sociologia da vida cotidiana, visto que seu objeto fundamental são os processos de transição e reprodução dos modos de produção nas mais diversas formações sociais. Ou seja, uma disciplina científica não pode ter a pretensão de abstrair da realidade todos os seus elementos nos seus detalhes mais mínimos, mas apenas aqueles cujas repercussões são pertinentes a sua problemática, no caso a reprodução ou a transformação das formações sociais. Como qualquer ciência, a ciência da história deveria ter categorias e um objeto construídos cognitivamente no intuito de aproximar-se sucessivamente do real sem nunca ter a ilusão de identificar-se com ele, portanto, na perspectiva do materialismo-histórico o empirismo ingênuo de Thompson afasta-se de uma teorização científica consistente. No que tange a tese da constelação de fatores cabe salientar que não se pretende negar que o real é a 
"unidade do diverso" ou a "unidade de múltiplas determinações", - que, no entanto, pretende-se afirmar é que o real é determinado por elementos que são complexos na sua própria constituição interna, portanto tais elementos podem e devem ser estudados tanto analiticamente, no sentido de se verificar sua estrutura e dinâmica imanente; quanto inseridos numa estrutura e dinâmica global, em que se verifica a sua eficácia e pertinência para o todo. Ou seja, os elementos que compõe o todo tem pertinência distinta e não equivalente. Com isso não se pretende afirmar também uma pertinência essencial que transcenda todo e qualquer contexto ou objeto de investigação, inclusive pretendese o contrário, ou seja, observar o deslocamento de eficácias e pertinências de acordo com o contexto observado e o problema construído. No caso colocado por Thompson, por exemplo, num estudo sociológico sobre relações familiares cotidianas é provável que a pertinência de ser mulher, esposa, amante e mãe seja maior do que ser operária e tesoureira do Partido Trabalhista. No entanto, não se pode transpor a eficácia e a pertinência dos elementos citados pelo autor para investigar, por exemplo, a mobilização operária contra o desmonte do Welfare State.

Assim, embora ofereçam contribuições importantes ao conhecimento do fenômeno das classes sociais no sentido econômico e político, os autores não trazem contribuições teóricas de fundo que possam servir a outras análises ou objetivos que transcendam a descrição e pretendam a explicação, pois ambos tratam os fatos como se esses fossem obviedades as quais poderiam ser observadas sem uma lente conceitual rigorosa. Desse modo, a descrição empirista do singular torna-se um limite instransponível para ambos. Por consequência, a menor alteração na realidade observada invalida automaticamente um conjunto de proposições, pois as analises são incapazes de observar as estruturas (regularidades) manifestas nas práticas (CASTRO, 2004). $\mathrm{Se}$ os fenômenos não podem ser explicados, apenas descritos, não é possível distinguir a contingência da necessidade e tudo se torna singularidade autorreferente, explicada somente pelos princípios da aleatoriedade e do voluntarismo.

\section{A contribuição teórica de Nicos Poulantzas}

No que concerne à exposição das concepções de Nicos Poulantzas a referência principal tomada é o texto Poder político e classes sociais (1977) que, embora faça parte da tradição 
marxista e tenha sido publicado no mesmo período das obras dos dois autores vistos anteriormente, se constitui como uma obra cujo propósito e ambição são consideravelmente diferentes. $O$ autor greco-francês produz e articula sistematicamente uma série de conceitos para a análise do político nas formações sociais capitalistas, ou seja, produz conceitos sobre a instância do político no modo de produção capitalista levando em consideração a necessária coerência teórica entre uma teoria geral dos modos de produção, uma teoria regional do político na teoria geral dos modos de produção, uma teoria particular do modo de produção capitalista e uma teoria regional do político na teoria particular do modo de produção capitalista. É por encarar tamanho desafio que o professor Décio Saes considera acertadamente que Poder político e classe sociais "se configura como o mais desenvolvido e sistemático tratado geral de teoria política marxista jamais publicado" (SAES, 1998, p.46).

Por tal motivo, Poulantzas se destaca dos autores supracitados na tradição marxista, pois ele oferece efetivamente um arcabouço teórico sistemático e multidimensional pelo qual se viabiliza a observação de objetos concretos distintos, transcendendo, portanto, os limites de uma descrição empírica encerrada em si mesma. Considerando, dessa maneira, que o objetivo do presente texto é apresentar uma justificação fundamentada do uso do referencial teórico poulantziano, não se pretende aqui apresentalo nas suas minúcias, mas destacar alguns pontos pelo quais tal referencial supera os problemas frisados nas teorias anteriormente apresentadas.

Sobre os problemas já ressaltados da teoria das elites vale retomar a sua circularidade explicativa derivada da concepção de autonomia absoluta da instância política, como se essa pudesse ser investigada somente a partir das suas determinações internas. À essa unilateralidade absolutizante costuma-se responder com outra unilateralidade, a do econômico, o que foi muitas vezes o caminho tomado por autores autodeclarados marxistas. Poulantzas, entretanto, não incorre nesse erro simplista e, desenvolvendo as teses althusserianas, toma o político a partir de uma perspectiva complexa, ou seja, considera a especificidade do político, sua estrutura e dinâmica endógena, sem desconsiderar, no entanto, sua relação permanente com as outras instâncias que constituem uma formação social, o ideológico e o econômico. Dessa maneira, em Poulantzas, o político é constituído por uma autonomia relativa, a qual é enfatizada no modo de 
produção capitalista pela própria autonomia relativa do Estado, que pode sacrificar os interesses econômicos da classe dominante em nome da reprodução da unidade dessa última como classe politicamente dominante. Nesse sentido o político é percebido como um sistema acoplado que é irritado pelo seu entorno e responde a esse com 0 intuito de se autorreproduzir pela reprodução do entorno no qual está acoplado5. Uma relação, portanto, complexa que considera determinações internas e externas.

No que concerne aos equívocos do pluralismo recupera-se a sua operação de redução arbitrária de determinantes múltiplos ao plano monodimensional dos grupos de interesse. Na perspectiva pluralista o modelo abstrato-formal não aparece como instrumento heurístico de investigação de um objeto concretoreal, ele mesmo torna-se o seu próprio objeto, assim, o modelo acaba se convertendo num meio para conhecer a si mesmo, ou seja, o próprio modelo. Considerou-se acima que tal procedimento teórico é deduzido de uma premissa ideológica, a saber, o efeito de isolamento produzido pela estrutura jurídicopolítica do Estado, ou seja, a atomização e a equalização jurídica dos agentes da produção, desconsiderando suas condições de desigualdade real no que tange às possibilidades de organização, intervenção, eficácia e pertinência. Na sociologia, essa operação que toma 0 efeito ideológico como premissa fundamental aparece quase sempre com a mobilização de dois conceitos: o de ator social (agente, sujeito, indivíduo, etc.) e o de sociedade. 0 primeiro reflete efetivamente $O$ efeito de isolamento, a equalização jurídica de todas as complexidades reais à categoria de cidadão portador de direitos; o segundo reflete a reunião desse simplismo formal num tempo e num espaço, sendo esses quase sempre indeterminados por aqueles que mobilizam a referida categoria. Poulantzas supera esse formalismo vazio ao desconsiderar um conceito geral capaz de abarcar determinações tão diferenciadas e imprecisas, dessa maneira não reduz tudo ao ator, ao agente, ao sujeito, ou até mesmo à classe. O autor de Poder político e classes sociais produz uma série diferenciada de conceitos determinados de modo multidimensional, nesse sentido diferencia, por exemplo: classes

\footnotetext{
${ }_{5}$ Numa tentativa de melhor explicitar a concepção poulantziana utilizou-se no referido período uma linguagem típica da teoria sistêmica (RODRIGUES e NEVES, 2017). A mobilização do léxico citado cumpre o papel de explicar por meio de uma homologia conceitual aquilo o que Poulantzas parece querer expressar. Tenta-se, desse modo, facilitar o entendimento do leitor, não se trata de uma incorporação, mesmo que retificada, de tais conceitos, o que demandaria uma atenção maior.
} 
sociais, frações de classe, categorias sociais, camadas sociais, classe dominante, classe hegemônica, classes-apoio, forças sociais, classe detentora, classe reinante, etc. Nota-se, portanto, uma série de articulações complexas que leva em consideração a amarração específica entre as regiões estruturantes e a amarração específica entre os elementos componentes dessas regiões. É no sentido, então, de conferir essa multidimensionalidade ao exame do fenômeno político e social que Poulantzas substitui o conceito unidimensional de sociedade, pelo conceito de formação social, caracterizado por uma matriz específica, ou seja, uma forma singular de articulação dos modos de produção e de suas respectivas instâncias - o ideológico, o político e o econômico. Por fim, afirma-se, desta maneira, que o reducionismo formalista operado pelo pluralismo é vencido pela teoria Poulantziana justamente porque no autor grego o abstratoformal dirige-se ao concreto-real, enquanto que na perspectiva pluralista o abstrato-formal é autorreferente, objeto de si mesmo.

No que tange aos marxismos anteriormente observados ressalta-se aqui não os problemas particulares já destacados de cada um deles, seja o do elitista ou do historicista, mas o seu núcleo comum de fundamentação, do qual os equívocos particulares constituem desdobramentos. Esse núcleo comum de fundamentação é, justamente, um núcleo comum marcado pela percepção da ausência de fundamento prévio, da qual se deriva uma perspectiva de ciência assistemática do ponto de vista teórico, que julga como possível capturar o empírico em estado puro, fora de um constructo teórico-cognitivo prévio. Nada mais que uma ingenuidade epistemológica. Esta perspectiva empirista, além de vulnerável, é também extremamente limitada no que tange a oferecer um instrumental teórico para abordagem de outros objetos que não aqueles referidos pela própria investigação. Poulantzas vence esse espontaneísmo empirista ao localizar sua obra num constructo sistemático mais amplo, fundamentado numa concepção epistemológica, teórica e metodológica previamente constituída. $O$ autor grego distingue e define 0 marxismo como unidade de duas disciplinas científicas, o materialismo histórico e o materialismo dialético. Defini o problema do materialismo histórico e o seu conceito fundamental: os modos de produção. Na teoria geral dos modos de produção localiza as instâncias que o constituem e as teorias particulares de cada modo de produção. Na teoria particular do modo de produção capitalista observa uma insuficiência, que é a ausência de uma 
teoria regional do político no modo de produção capitalista. Nesse sentido, propõe-se a articular todo esse arcabouço prévio com pesquisa teórica na perspectiva de produzir uma teoria regional do político na teoria particular do modo de produção capitalista contida na teoria geral dos modos de produção, 0 materialismo histórico. Trata-se, portanto, de um esforço científico sistemático capaz de distinguir efetivamente 0 materialismohistórico de uma ciência sensualista da história, de uma massa indistinguível de conceitos indefinidos e desarticulados e do próprio senso-comum. Por conseguinte, o autor oferece um instrumental teórico para a investigação científica do político nas formações sociais capitalistas, não limitando sua produção à descrição empírica de um objeto singular. Assim sendo, pode ser considerado como aquele que melhor atendeu às necessidades que mobilizaram a já mencionada pesquisa exploratória de caráter teórico que o presente texto relata.

\section{Considerações finais}

Buscando explicitar até aqui uma apreciação crítica de diferentes arcabouços teóricos no sentido de oferecer justificadamente um referencial adequado à construção de uma problemática de pesquisa ainda em estado embrionário, conclui-se como resultado da pesquisa exploratória descrita, que a teoria regional do político de Nicos Poualntzas é aquela que melhor adequa-se ao objetivo proposto. Tal conclusão, bem como a argumentação que a ensejou, não tem como finalidade o desmerecimento das concepções descartadas, visto que todas elas, algumas mais outras menos, trouxeram contribuições valiosíssimas, sem as quais a teoria Poulantziana não poderia se constituir da maneira como se constitui. Ademais, não se estabeleceu como pretensão do presente texto a construção de uma enciclopédia crítica do pensamento político e sociológico para, enfim, se atestar a teoria absoluta, o ponto de chegada do pensamento social. Ou seja, a própria obra de Poulantzas contém inconsistências e imprecisões, devendo também ser tomada como objeto de crítica para o desenvolvimento teórico das Ciências Sociais. No entanto, no interior dos limites de conhecimento teórico do autor do presente texto o tratado poulantziano foi considerado o mais robusto, sendo também o mais útil para transformar uma determinada pergunta de partida ainda ingênua num problema de pesquisa minimamente consistente. 
Exploração teórica para a investigação da interface entre o político e o econômico

\section{Referências bibliográficas}

ALtHUSSER, Lovis. Por Marx. Campinas, SP: Editora da Unicamp, 2015.

BOITO JR, Armando. Estado, Política e classes sociais. São Paulo: Editora Unesp, 2007.

BOURDIEU, Pierre. Razões Práticas: sobre a teoria da ação. Campinas, SP: Papirus, 1996.

BRASIL. LEI ORDINÁRIA N 12351, DE 22 DE DEZEMBRO DE 2010. Dispõe sobre a exploração e produção de hidrocarbonetos sob o regime de partilha. Brasília, DF, 2010. Disponível em http://www.planalto.gov.br/ccivil_03/ato20072010/2010/lei/L12351.htm

CASTRO, Flávio. O Estado do modo de produção capitalista em Poulantzas e Miliband: conflito ou complemento?, Cadernos Cemarx, Campinas, $n^{\circ} 1$ : p. 75-81, 2004.

CREMONESE, Djalma. A questão da participação na Teoria Democrática Contemporânea. Seminário Nacional de Ciência Política: Democracia em Debate Universidade Federal do Rio Grande do SUI - UFRGS, GT Cultura Política e Opinião Pública, 2008.

DAHL, Robert A. A democracia e seus críticos. São Paulo: Editora WMF Martins Fontes, 2012.

ENGELS, Friedrich. A origem da família, da propriedade privada e do Estado. Rio de Janeiro: Civilização Brasileira, 1981.

GIMENEZ, Éder Rodrigues. Teoria das elites e as elites do poder: considerações sobre a relevância dos teóricos clássicos e de Wright Mills aos estudos de cultura política e democracia. São Carlos: Revista de Discentes de Ciência Política da UFSCAR, Vol.2 - n.2 - 2014.

LENIN, Vladimir I. O Estado e a Revolução. São Paulo: Editora Expressão Popular, 2010.

MARX, Karl. O Dezoito do Brumário de Luís Bonaparte. São Paulo: Editora Martin Claret, 2008.

A Crítica da Filosofia do Direito de Hegel. São Paulo: Boitempo, 2010.

MARX, Karl; ENGELS, Friedrich. O Manifesto do Partido Comunista. Porto Alegre: LEPM, 2011.

MILIBAND, Ralph. O Estado na Sociedade Capitalista. Rio de Janeiro: Zahar Editores, 1972.

POULANTZAS, Nicos. Poder Político e Classes Sociais. São Paulo: Martins Fontes, 1977. 
Exploração teórica para a investigação da interface entre o político e o econômico

O Estado capitalista: uma resposta a Miliband e Laclau. Revista Crítica Marxista, Campinas, $n^{\circ} 27$ : p. 105-129, 2008.

RODRIGUES, Léo P.; NEVES, Fabrício M. A Sociologia de Niklas Luhmann. Petrópolis, RJ: Vozes, 2017.

SAES, Décio. Uma contribuição à crítica da Teoria das Elites. Campinas: Revista de Sociologia e Política, n³, 1994.

A questão da autonomia relativa do Estado em Poulantzas. In: Revista Crítica Marxista. Rio de Janeiro: Xamã, n7, 1998.

THOMPSON, Edward P. A miséria da teoria ou um planetário de erros: uma crítica ao pensamento de Althusser. Rio de Janeiro: Zahar editores, 1981.

A Formação da Classe Operária Inglesa. Rio de Janeiro: Editora Paz e Terra, 2004. 